\title{
Laryngeal Route of Administration
}

National Cancer Institute

\section{Source}

National Cancer Institute. Laryngeal Route of Administration. NCI Thesaurus. Code C38282.

Administration of a drug directly upon the larynx. 